\title{
Effect of co-administration of donepezil and folic acid on spatial memory impairment in adult male rat model of Alzheimer's disease
}

\author{
$\underline{\text { A. Eskandary }}^{1}$, AA. Moazedi ${ }^{1}$ \\ ${ }^{1}$ Department of Biology, Faculty of Sciences, Shahid Chamran University, Ahvaz, Iran \\ Corresponding Address: Azade Eskandary, Department of Biology, Faculty of Science, Shahid Chamran University, \\ Ahvaz, Iran \\ Tel: +98-916-3608155. Email: azade.eskandary@ gmail.com \\ Received: 11 Aug 2018; Accepted: 14 Oct 2018
}

* Abstract

Background: Alzheimer's disease is a neurodegenerative disorder that is diagnosed with a lack of memory and perception.

Objective: The aim of this study was to evaluate the effect of donepezil and folic acid on reference and working memory disorders caused by electrical lesion of nucleus basalis magnocellularis (NBM).

Methods: In this experimental study, 49 adult male Wistar rats were divided into 7 groups: control and, nucleus basalis magnocellularis (NBM) lesion group. which received electrically-induced lesion $(0.5 \mathrm{~mA}, 3 \mathrm{~s})$ in NBM, sham group (the electrode was impaled in to the nucleus basalis magnocellularis with no lesion), donepezil group (lesion + donepezil $0.1 \mathrm{mg} / \mathrm{kg}$ ), folic acid group (lesion + folic acid $5 \mathrm{mg}$ ), interaction group (lesion + donepezil-folic acid) and vehicle group (lesion + saline). Acquisition and retention tests were done by using an eight-radial arm maze task.

Findings: Results showed that there was a significant difference between control and lesion groups $(\mathrm{P}<0.05)$. Combination treatment with donepezil and folic acid improved the parameters of spatial memory errors in the acquisition and retention tasks comparing to the control group ( $\mathrm{P}$ 0.05).

Conclusion: The degradation of the nucleus basalis magnocellularis caused to increase reference and working memory errors. Also the co-administration of donepezil and folic acid leaded to a reduction in these errors and improved spatial memory of the rat.

Keywords: Alzheimer's disease, Nucleus basalis magnocellularis, Donepezil, Folic acid, Memory Citation: Eskandary A, Moazedi AA. Effect of co-administration of donepezil and folic acid on spatial memory impairment in adult male rat model of Alzheimer's disease. J Qazvin Univ Med Sci 2018; 22(5): 14-25. 


\title{
اثر تجويز توأم دونيزيل و اسيد فوليك بر اختلالات حافظه فضايى در موش صحر ايیى نر بالغ مدل بيمارى آلزايمر
}

\author{
آزاده اسكندرى'، دكتر احمدعلى معاضدى'
}

أرووه زيستشناسى دانشكده علوم دانشخاه شهيد حمر ان اهواز، اهواز، ايران

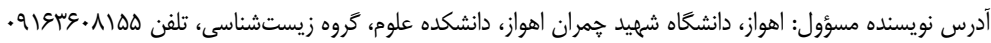

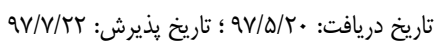

زمينه: بيمارى آلزايمر يك بيمارى تحليل برنده عصبى است كه با فقدان حافظه و ادراك مشخص مئرَّردا.

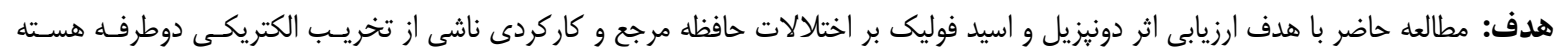
قاعدهاى مخنوسلولاريس انجام شد.

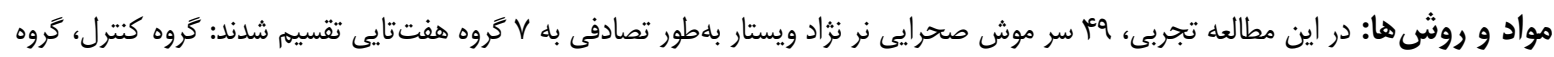

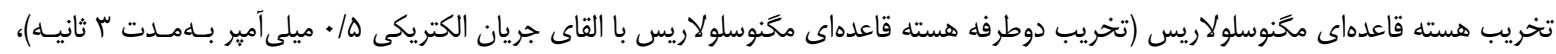

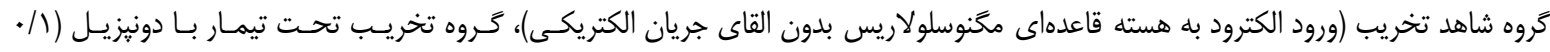

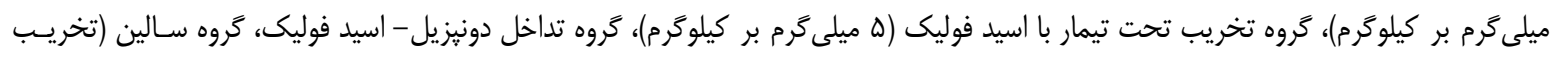

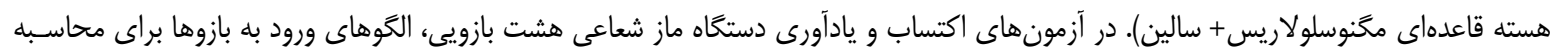

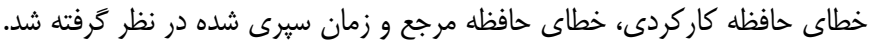

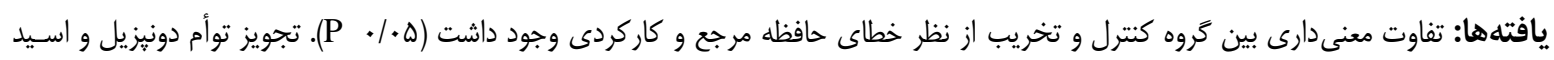

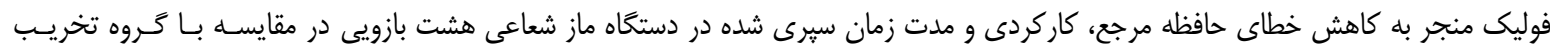

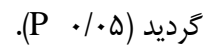

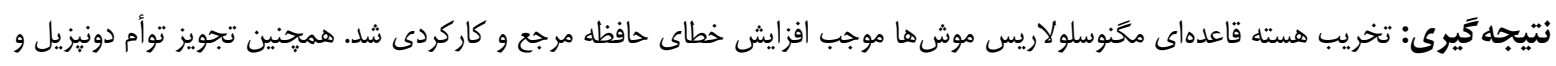

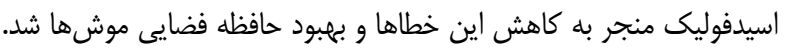
كليدوازهها: بيمارى آلزايمر، هسته قاعدهاى مكَنوسلولاريس، دونيزيل، اسيد فوليك، حافظه

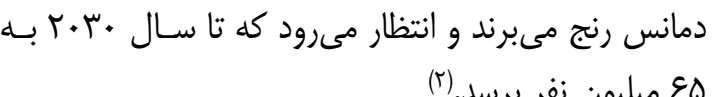

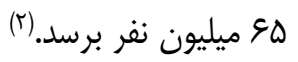

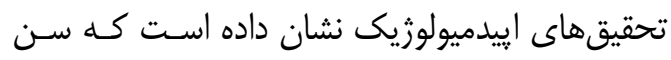

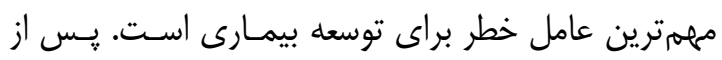

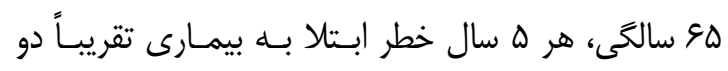

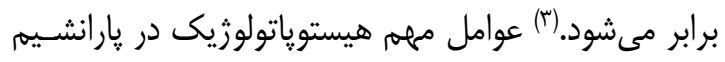

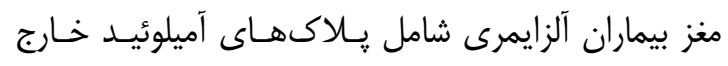

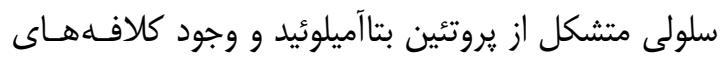

\section{مقدمه:}

بيمارى آلزايمر يكى از شايعترين بيمـارىهـاى دوران

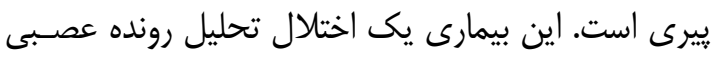

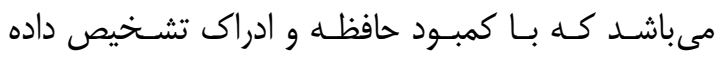

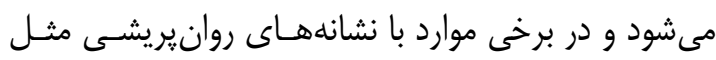

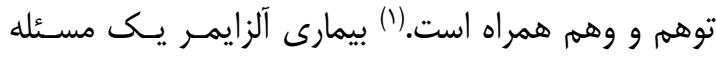

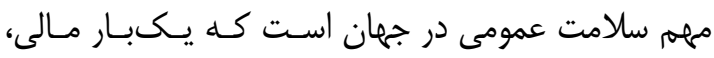

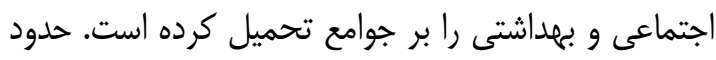

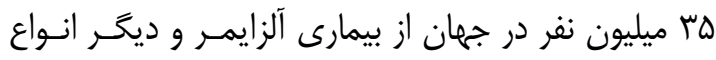




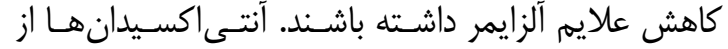

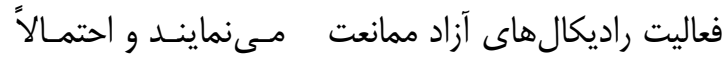

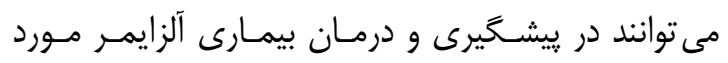
استفاده قرار كيرند.(II)

اسيد فوليك يا ويتامين B6، از تروه ويتامينهـاى B، براى بسيارى از عملكردهاى بدن از جمله سلامت سيسته

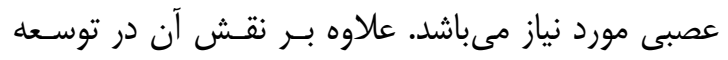

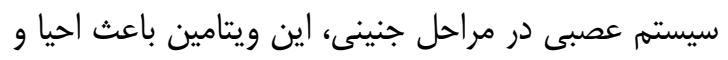
بازسازى بخشهاى آسيب ديده مغز و نخاع در افراد مبتلاينا

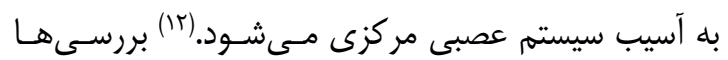

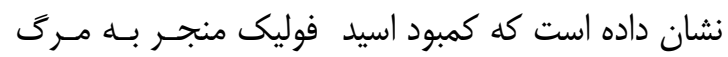

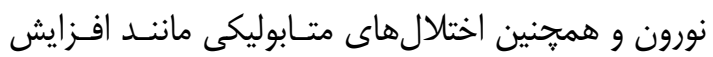
اسيد آمينه هموسيستئين مـىشـود كـه عامـل مهمهى در

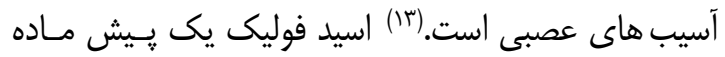

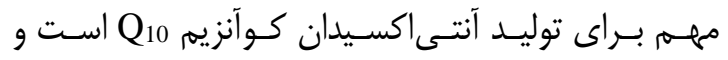

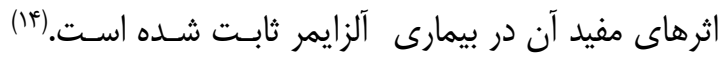

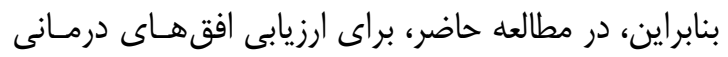
مؤثرتر در بهبود اختلالهاى شـناختى، اثربخشى درمـان

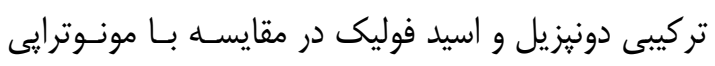
هر يك از داروها مورد بررسى قرار گرفت.

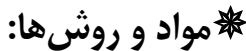

در اين مطالعه تجربى تعداد ؤ سر موش صحرايى نر

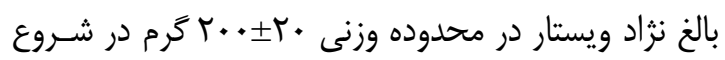
آزمايش از مركز تكثير دانشكاه علوم يزشكى جُندى شايور

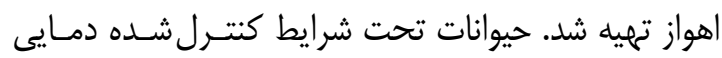

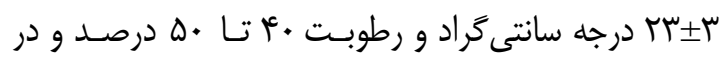

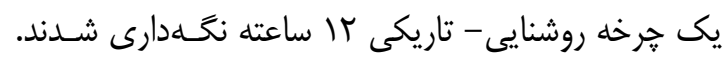

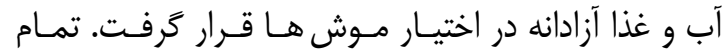

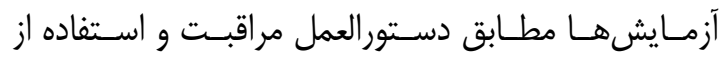

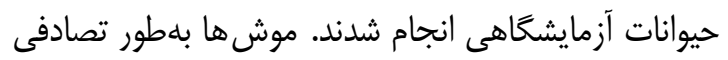

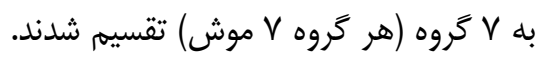

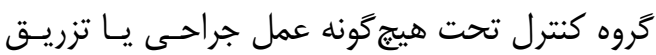

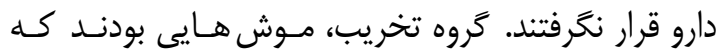

نوروفيبريلارى داخل نورونى متشكل از يروتئينهاى هايير

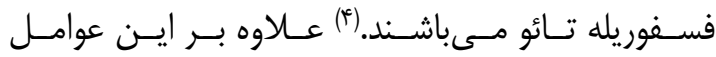

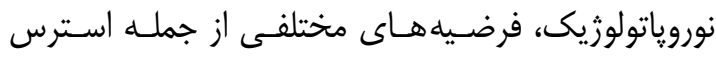

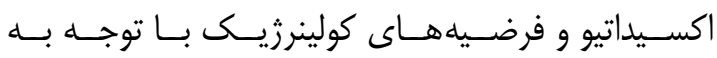

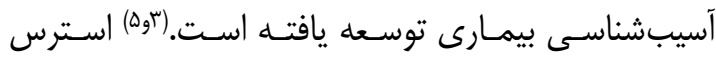

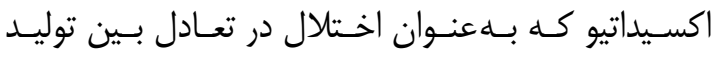

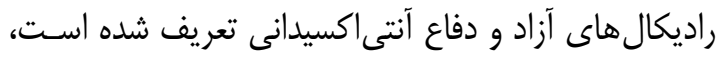

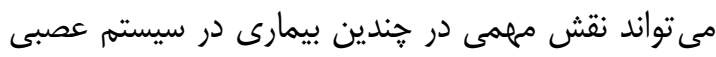

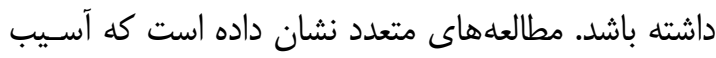

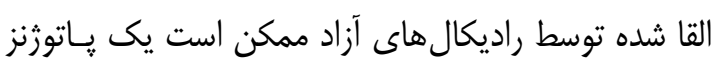

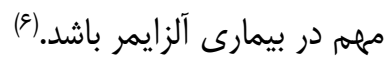

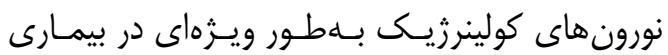

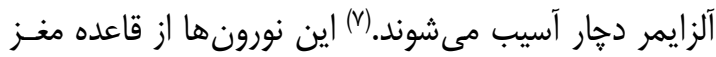
جلويى، ناحيهاى به نام هسـته قاعـدهاى مخَنوسـلولاريس (Nucleus basalis of magnocellularis; NBM)

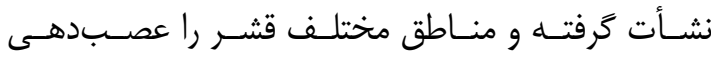

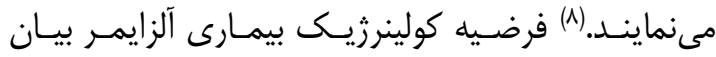

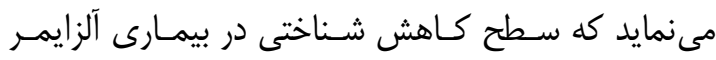

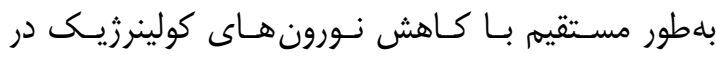
NBM

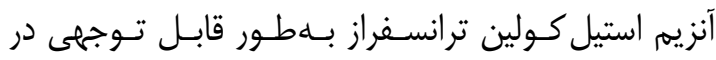

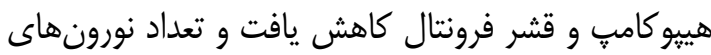

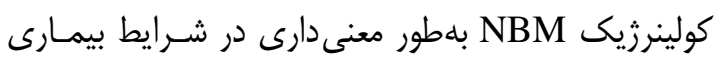
آلزايمر پايينتر بود. در حال حاضر، مهمار كنندهــاى اسـتيل كـولين اسـتراز

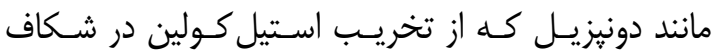

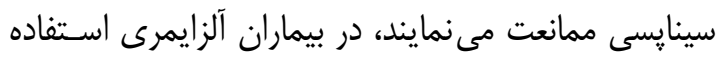

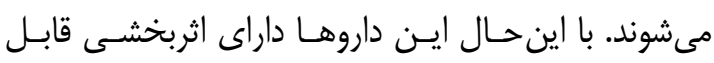

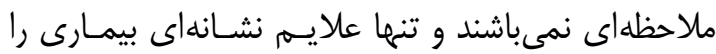

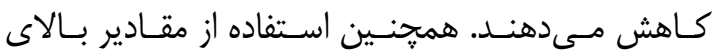

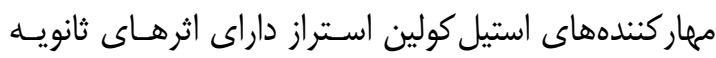

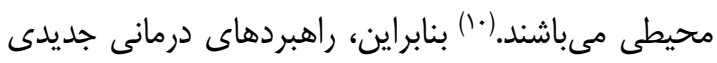

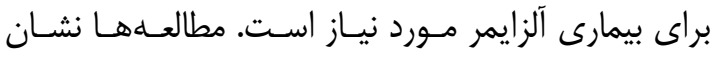

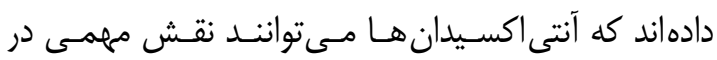


تك قطبى تخريبى در نقطه مـورد نظـر (جــس هِاتـين،

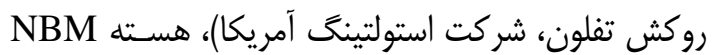

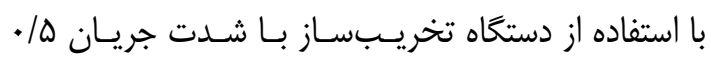

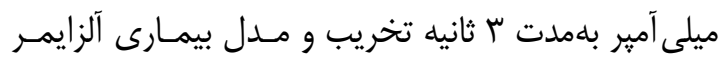

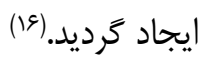

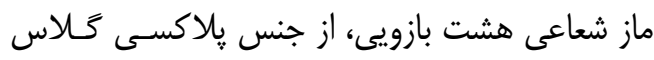

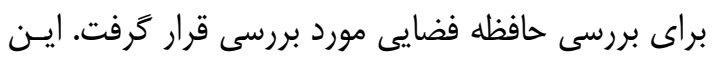

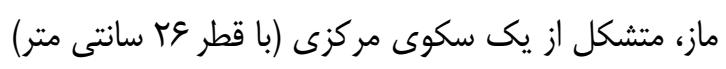

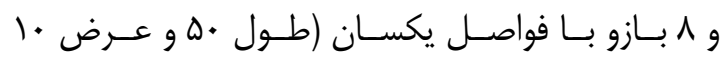

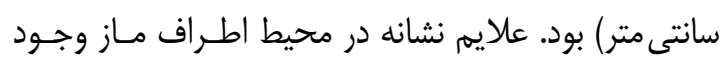
داشت كه در طول دوره آزمايش در مكان هاى ثابتى قـرار

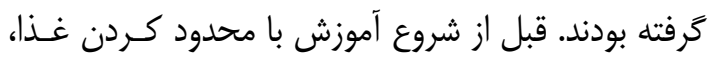

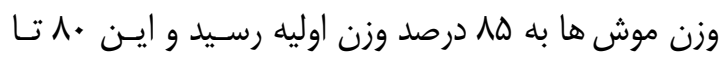

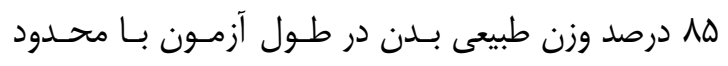

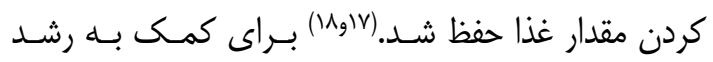

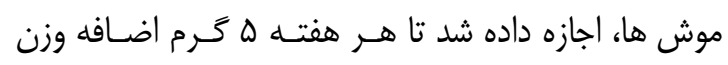

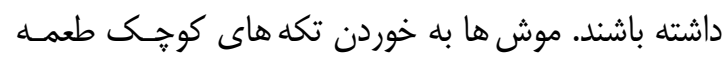

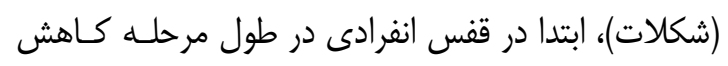

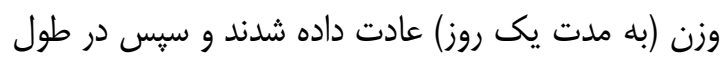

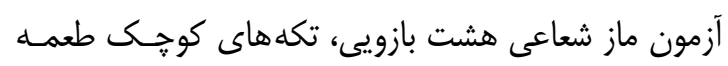
بلهصورت روزانه و با وزن هأ ميلى گرم آماده شد.

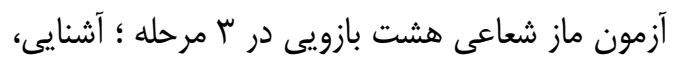

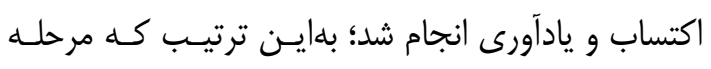

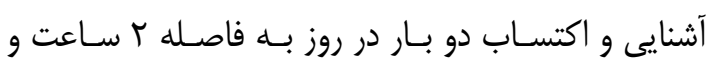

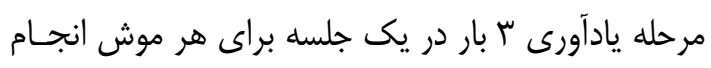

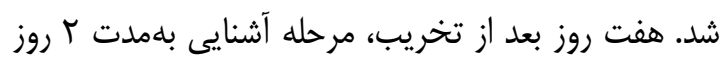
انجام شد كه در اين مدت؛ همه بازوها با غذا طعمه كذارى

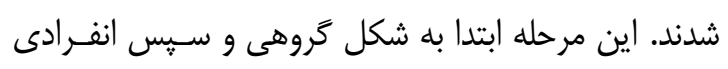

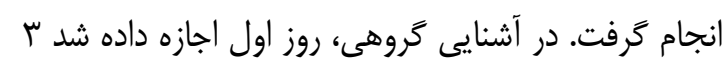

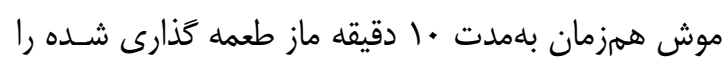

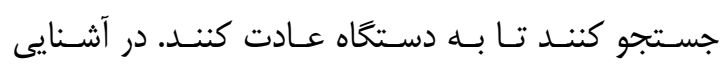

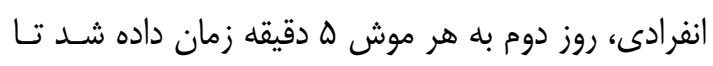

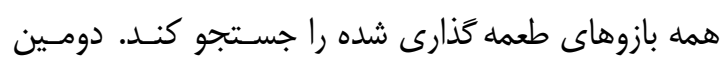

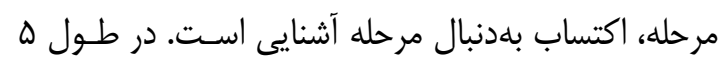

جهت مدل آلزايمر، هسته NBM آن ها بهصورت دو طرفه

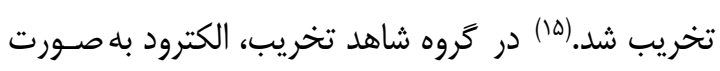

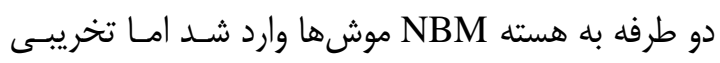

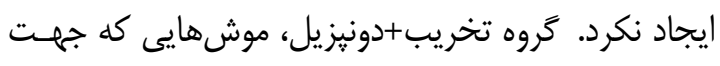

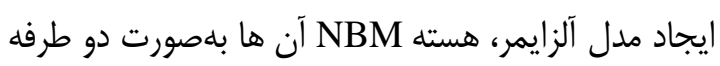

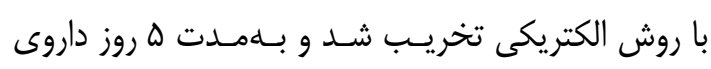

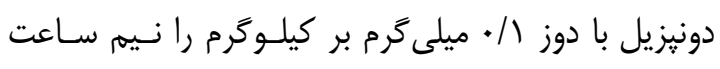

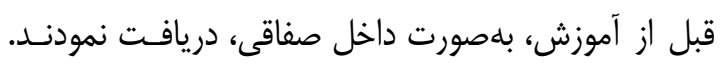

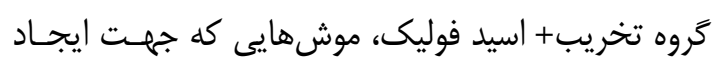

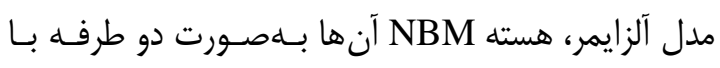

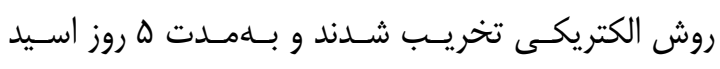

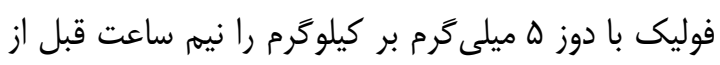

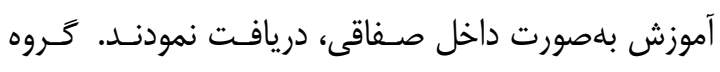

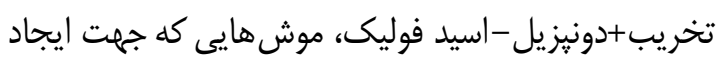

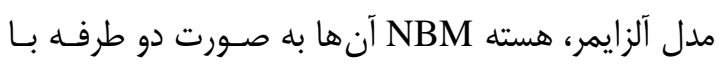

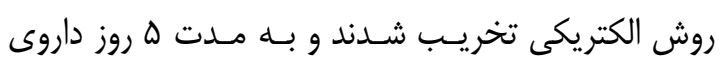

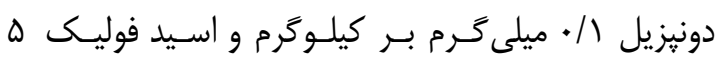

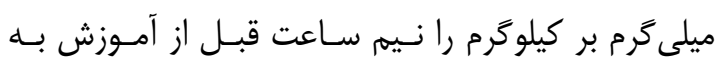

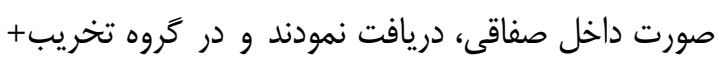

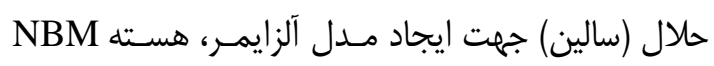

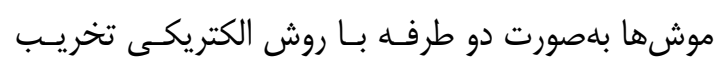

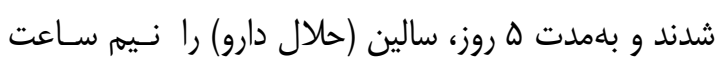

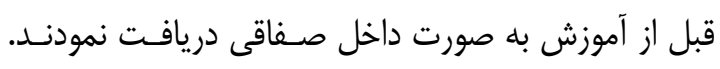

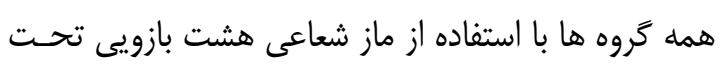
آزمون اكتساب و يادآورى قرار ترف فتند. جهت تخريب هسـته NBM، حيوانـات آزمايشـاهـى

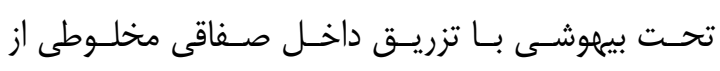

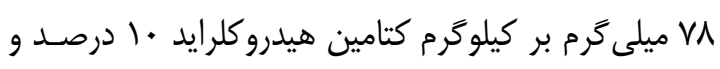

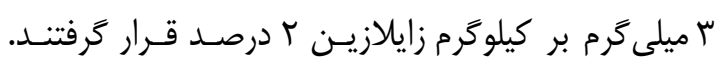
براى تخريب اين هسته، از دستخاه استر يوتاكسى (شركت

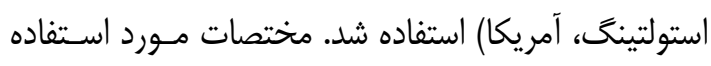

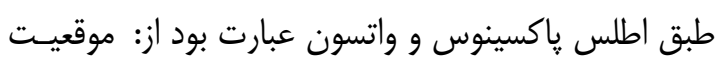

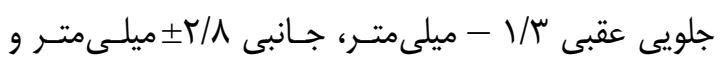

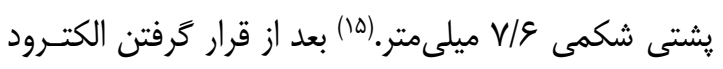




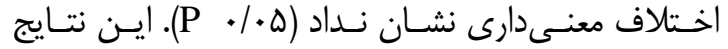

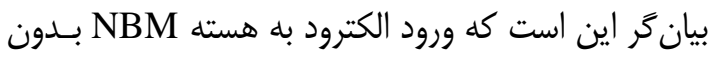

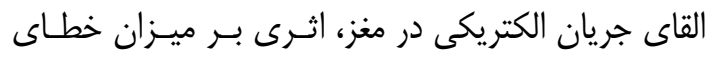

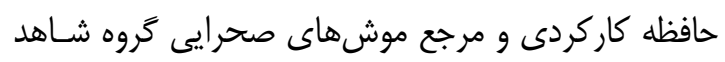

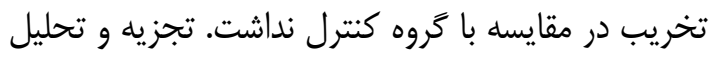
دادهها بيانگر اين است كه تخريب دوطرفه هسته

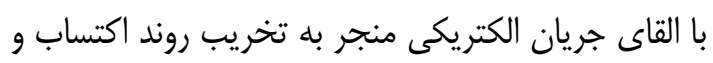

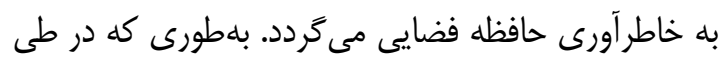

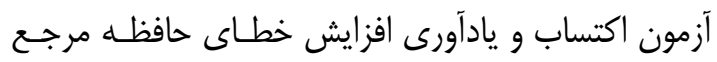

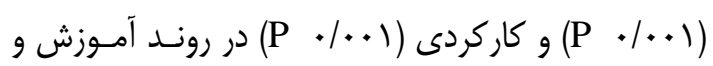

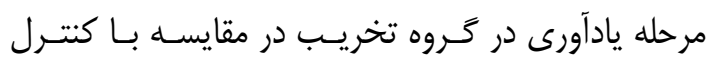

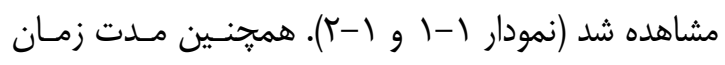

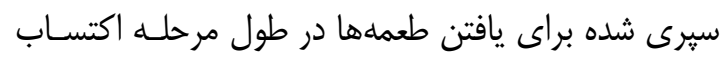

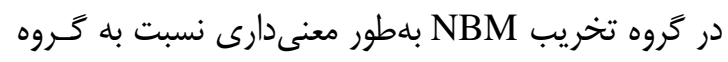

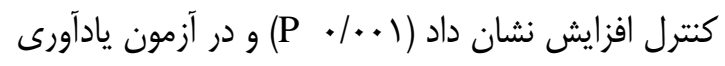

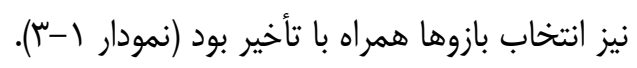

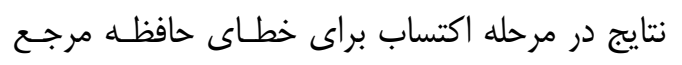

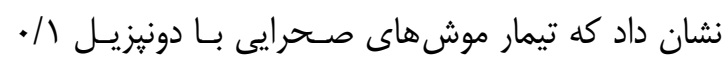

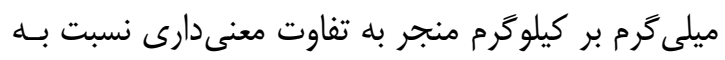

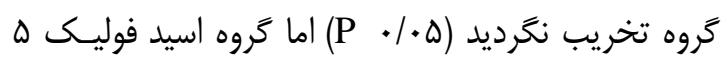

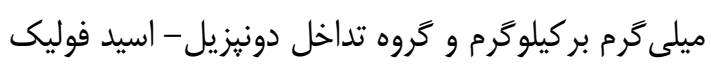

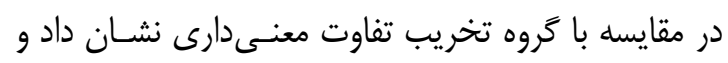

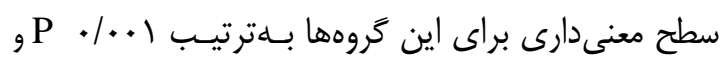

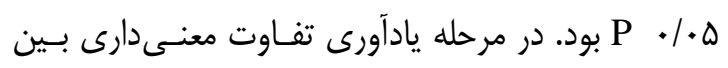

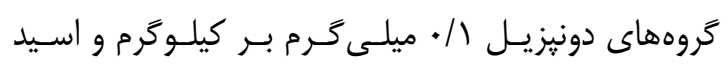

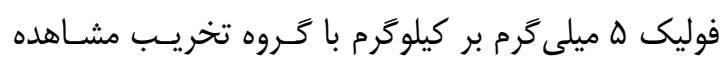

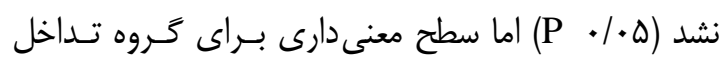

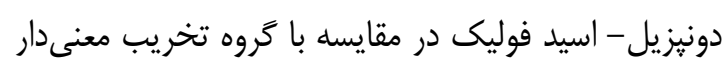

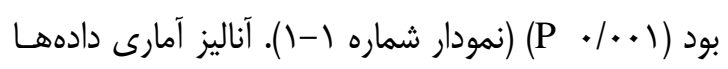

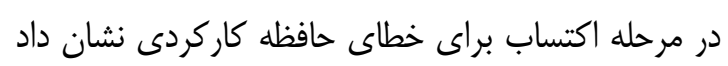

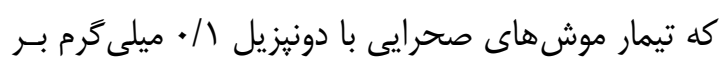

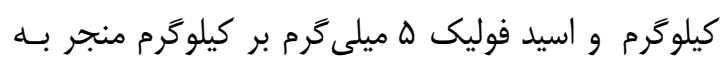

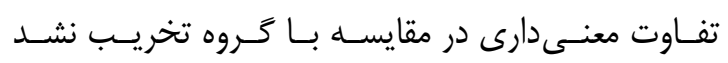

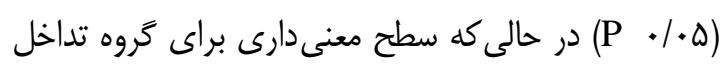

روز دوره آموزش، ع بازو از 1 بازو طعمه كذارى شد. الحَوى

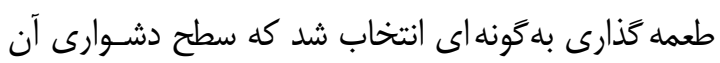

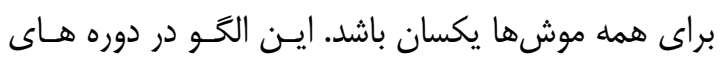

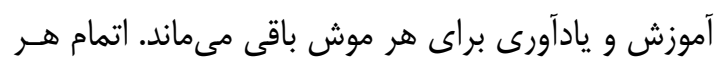

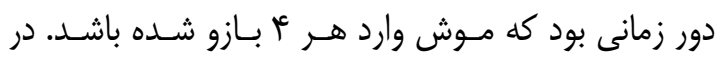

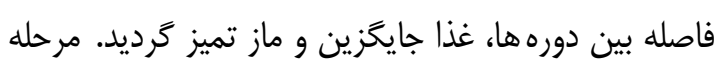

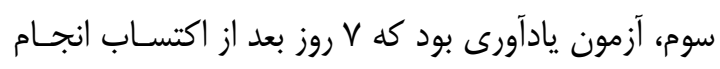

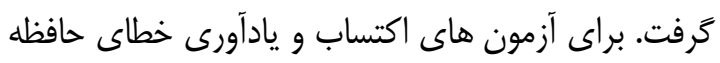

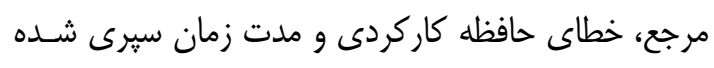

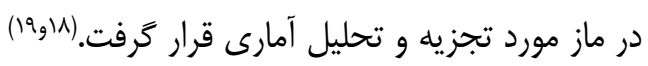
در ماز شعاعى هشت بازويى، موش ها بايد ياد بحيرنسـ

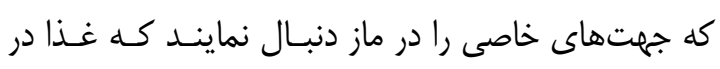

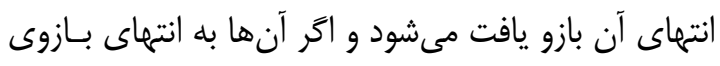

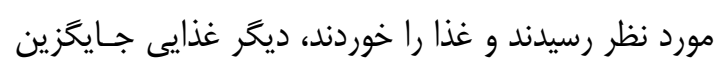
آن نمى شود (اكتساب). در مقابل، بعد از يادَّيرى در طول

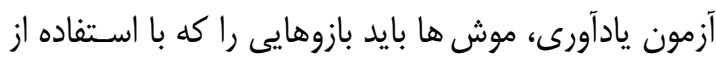

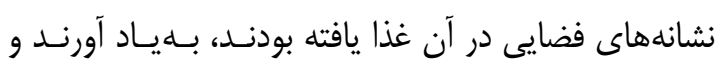

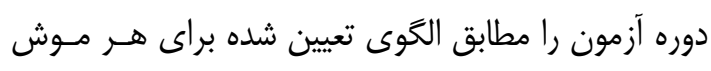

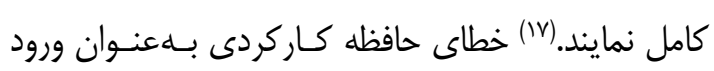

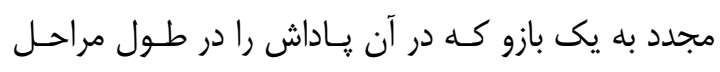

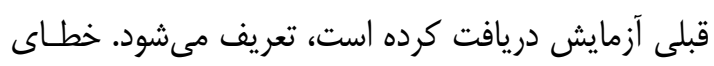

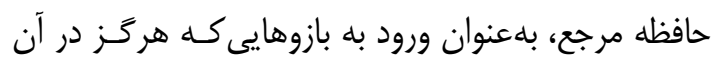

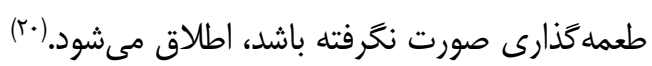

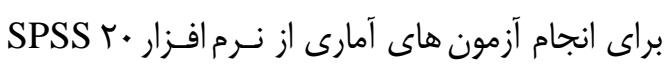

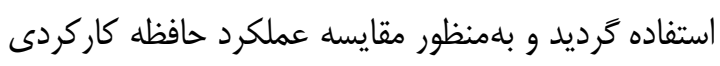

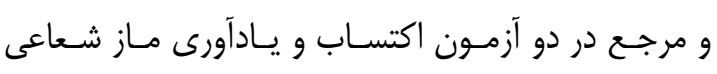

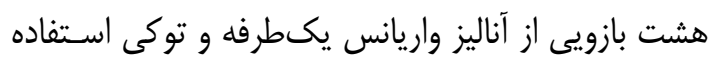

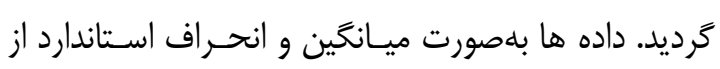

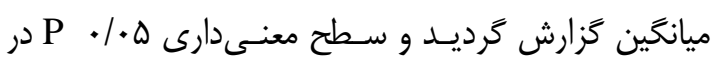
نظر كرفته شد.

\section{(2) يافتهها:}

مقايسه تروه هاى شـاهد تخريسب و كنتـرل در طـول

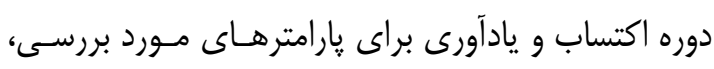


مقايسه با گروه تخريب تفاوت معنسى دارى مشـاهده نشـــ

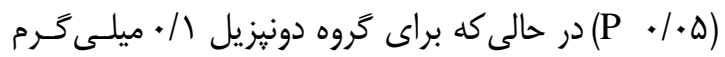

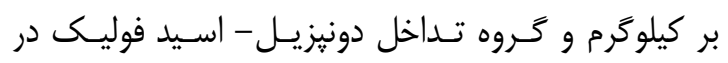

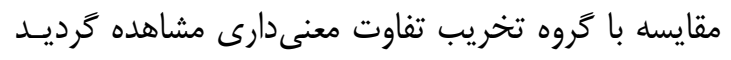

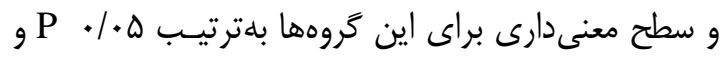

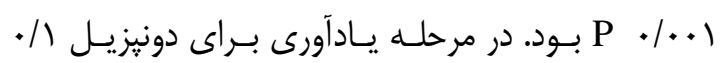

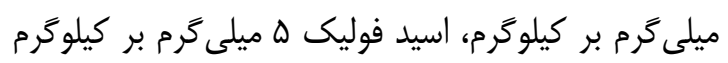

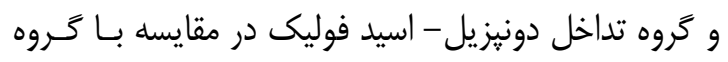

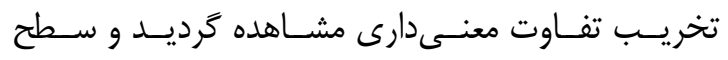

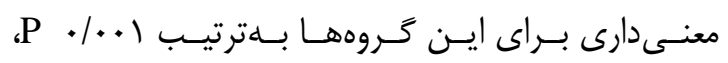

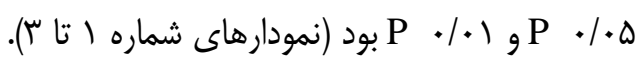

دونيزيل - اسيد فوليك در مقايسه با تروه تخريب معنى دار

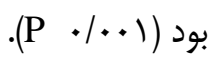
در مرحله يادآورى تفاوت معنى دارى بين خـروه اسـيد

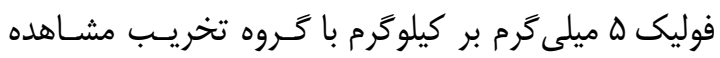

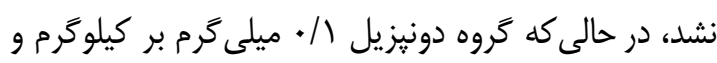

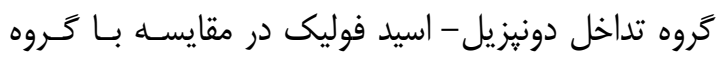
تخريب تفاوت معنىدار مشاهده كَرديد و سطح معنى دارى درى

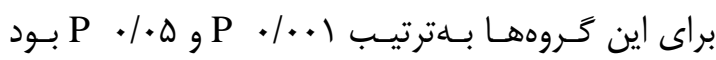

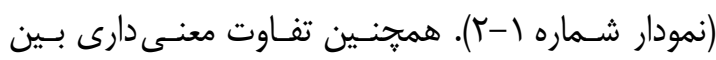

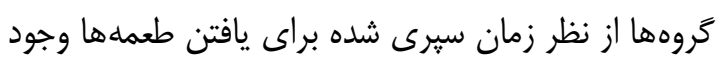

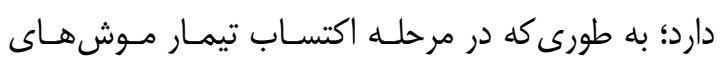

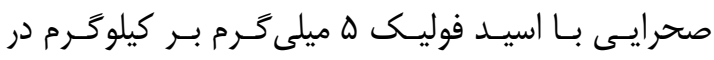

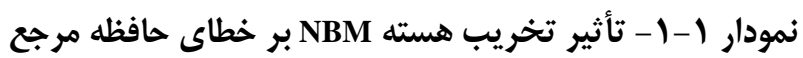

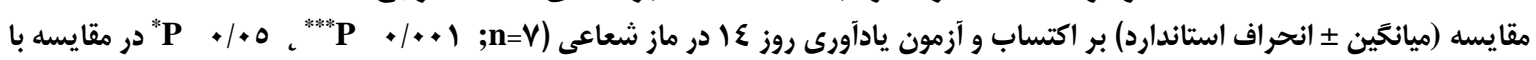

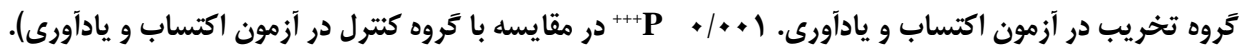

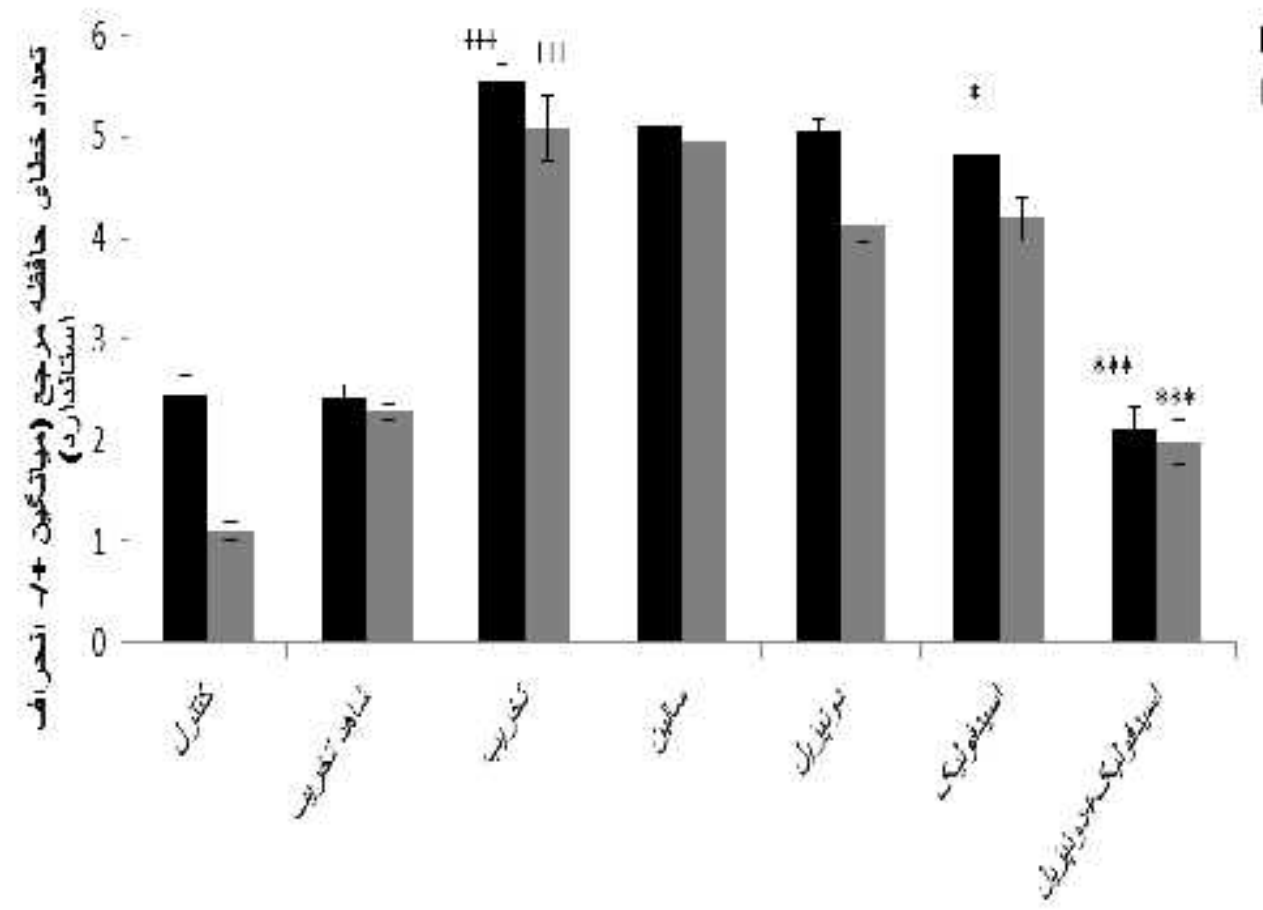

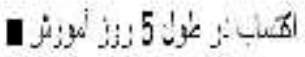
III 


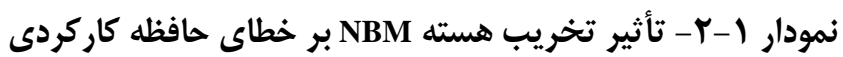

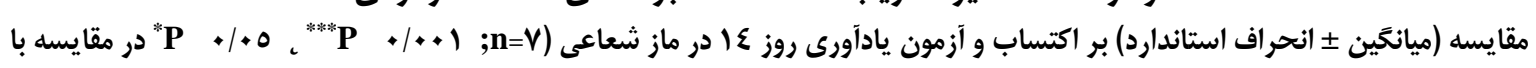

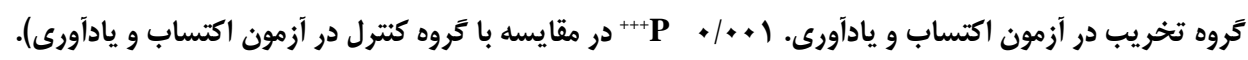

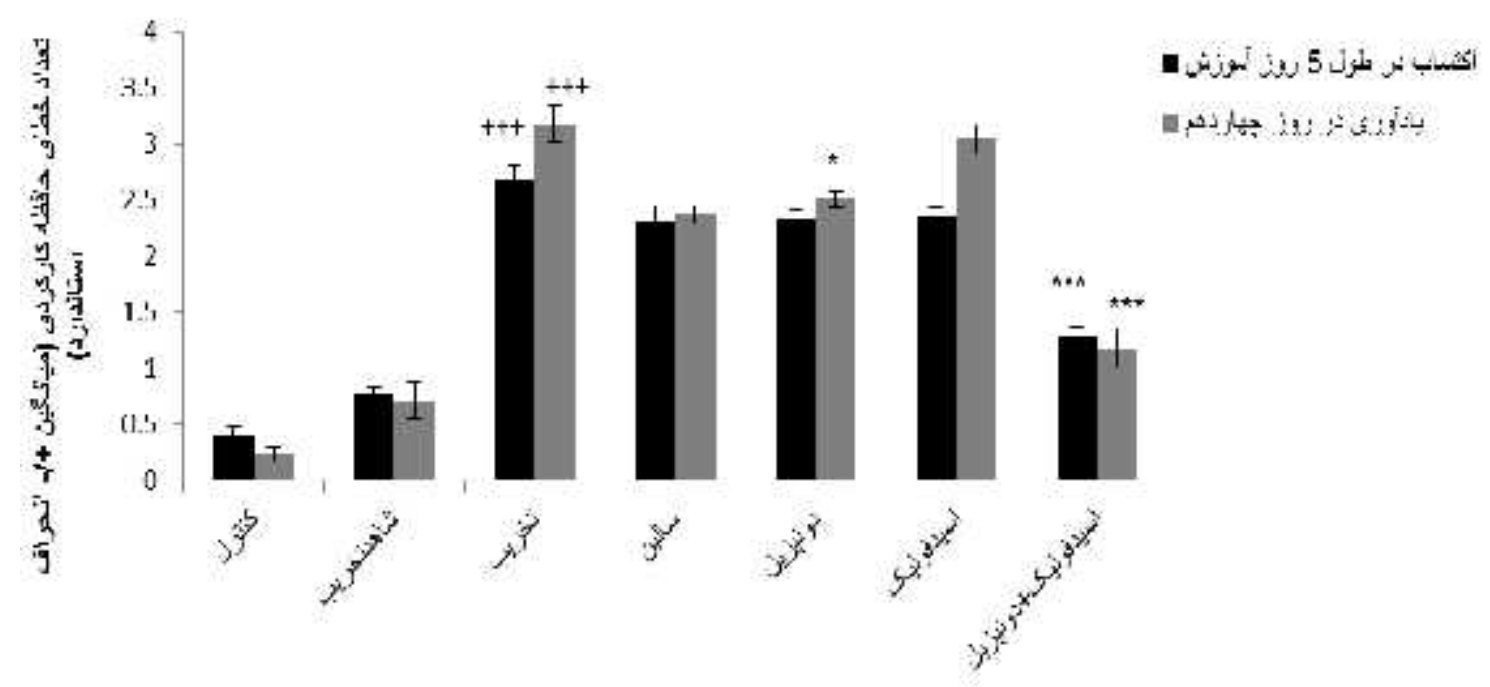

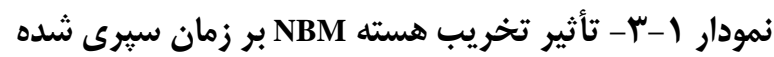

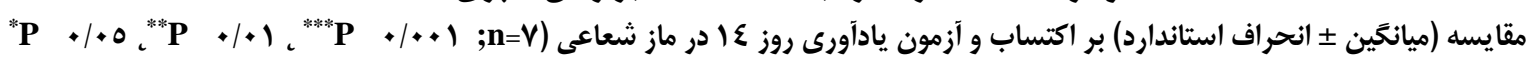

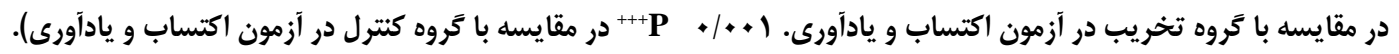

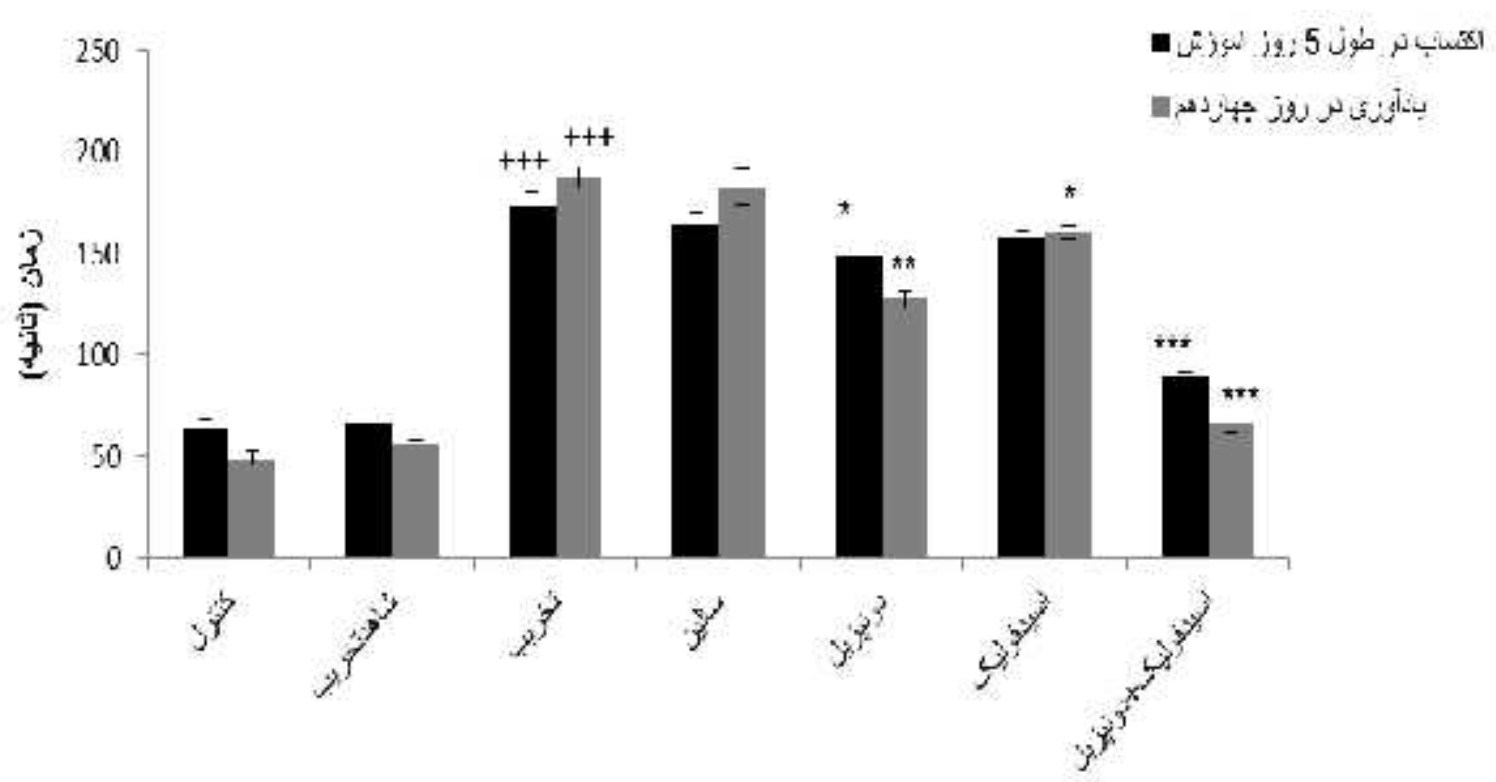


تيمار موشهاى صحرايى با دونيزيـل / / ميلــــرم بـر

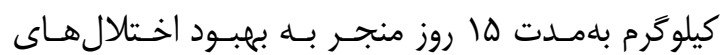

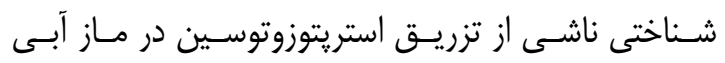
موريس مى گردد. (19)

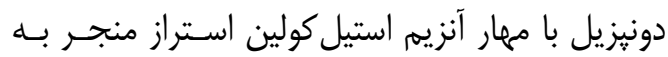

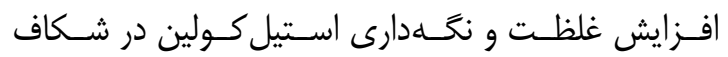

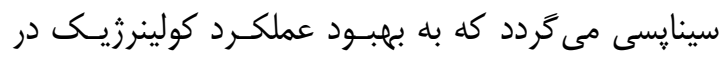

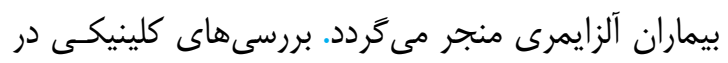

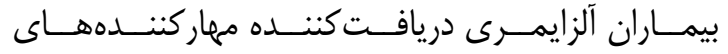

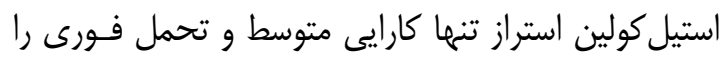

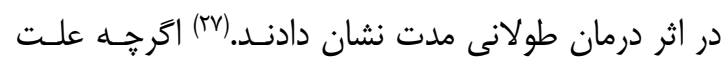

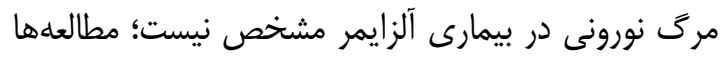

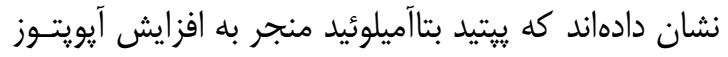

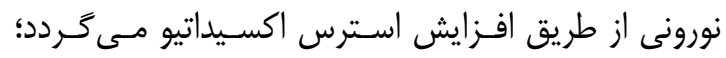

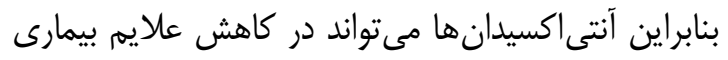

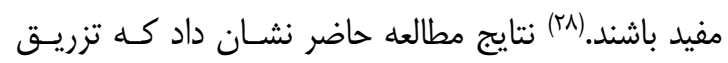

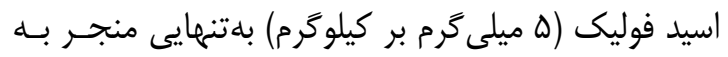

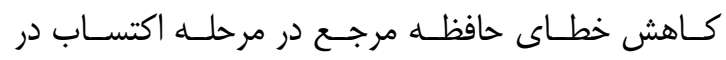

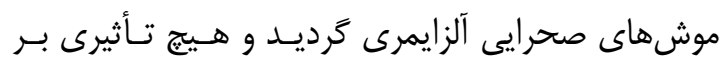

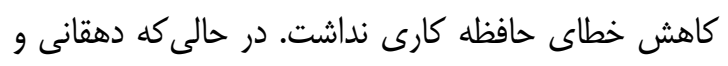

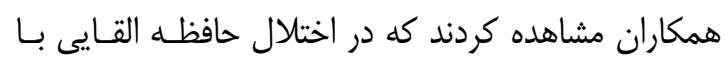

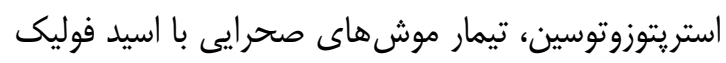

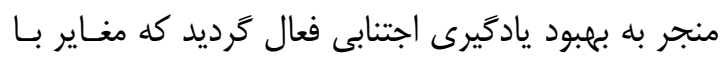
مطالعه حاضر است.(rq) يثوهش حاضر همجنين نشـان داد كـهـ تزريـق تـوأم

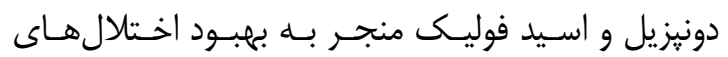

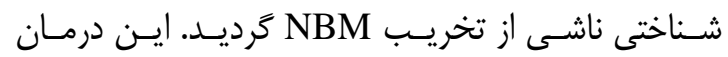

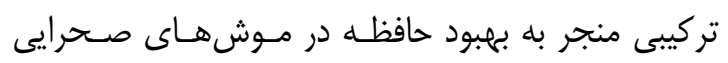

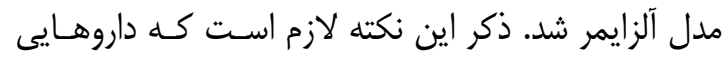

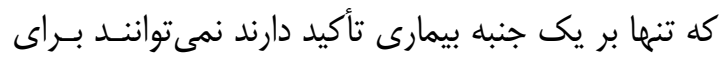

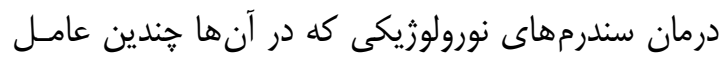

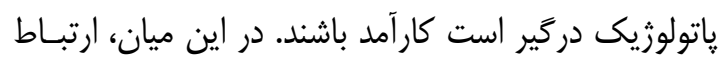

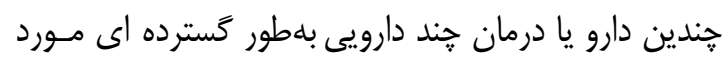

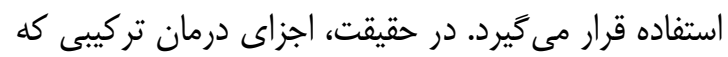

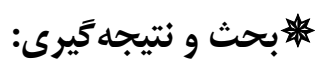

بررسى ها در جوندكان، يريماتها و انسان نشـان دان داده

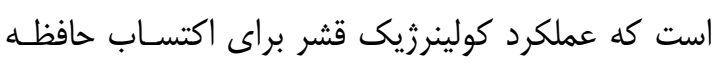

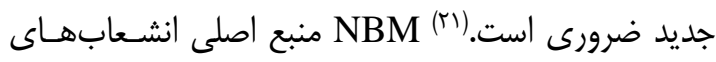

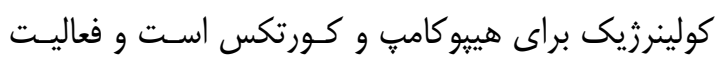

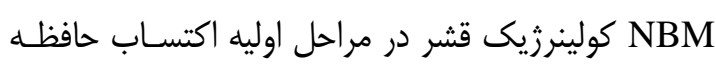

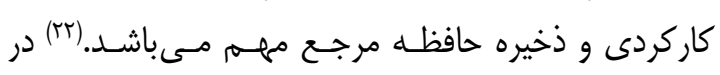

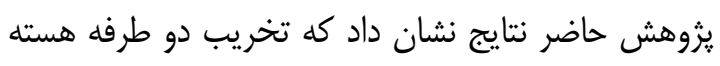
NBM بلهوسيله جريان الكتريكى در موش صحر ائى منجر

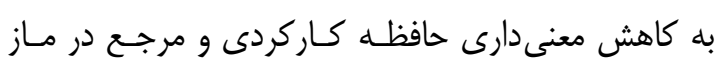
شعاعى هشت بازويى در مقايسه با گروه كنترل گر ديد.

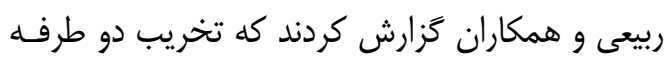
هسته NBM با روش الكتريكى باعث كـاهش يـادئي

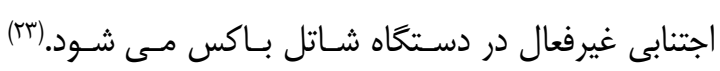

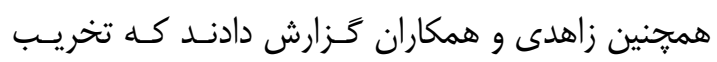

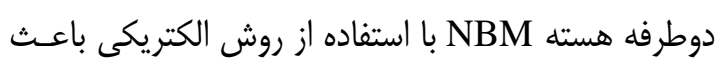

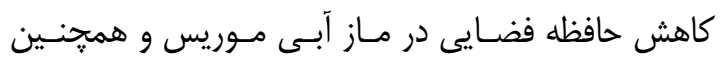

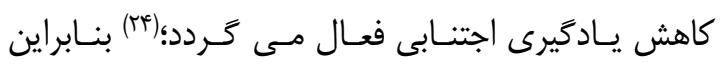

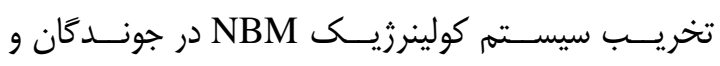
يريماتها باعث كاهش عملكرد كولينرزيكى قشر مى ترَّد

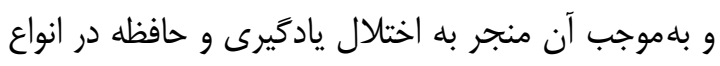

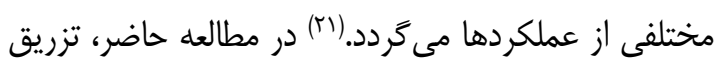

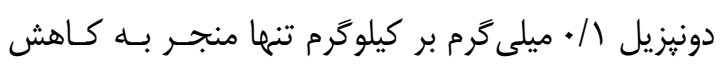

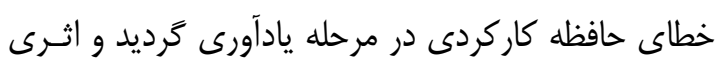

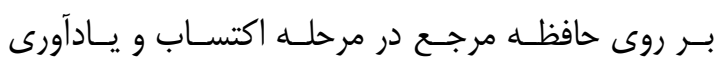

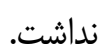

ليندر و همكاران كزارش كردند كه تزريق اسكويولامين

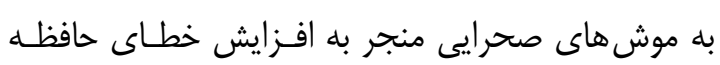

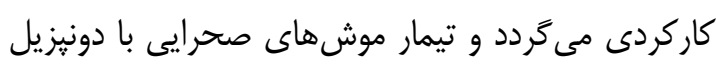

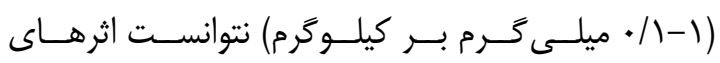

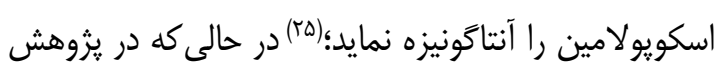

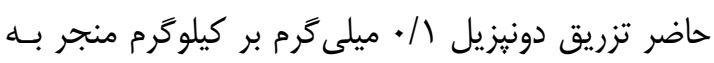

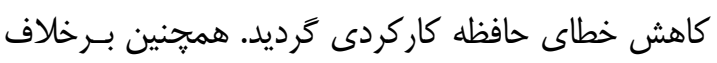

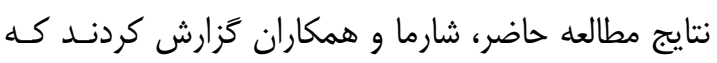


يزوهش، احتمالاً بهدليل تفاوت نوع تزريق و عامـل زمـان

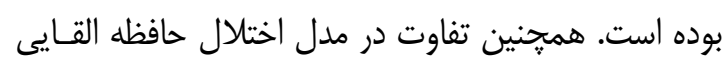

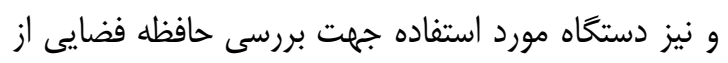

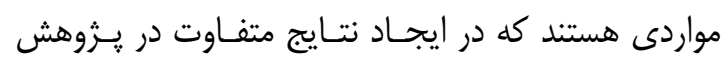

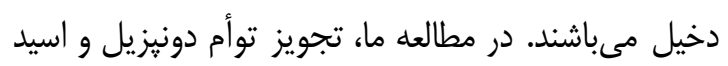

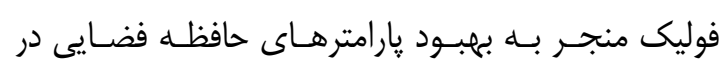

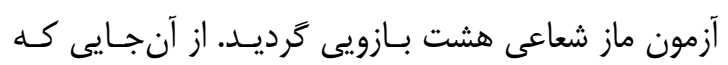

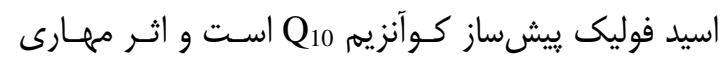

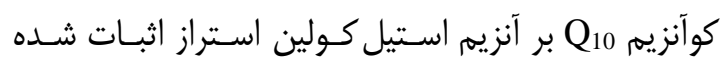

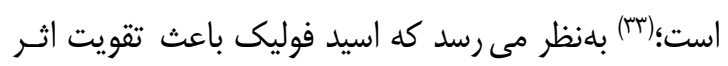

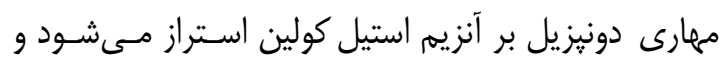
حافظه فضايى را بهبود مى بخشد.

$$
\text { مورد تأييد قرار كَرفت. }
$$

\section{مراجع:}

1. Dumont D, Beal MF. Neuroprotective strategies involving ROS in Alzheimer's disease. Free Radic Biol Med 2011; 51(5): 1014-26. doi: 10.1016/j.freeradbiomed.2010. 11.026.

2. Koroler I.O. Alzheimer's disease: a clinical and basic science review. Medical Student Research J 2014; 4: 24-33.

3. Ferreira ME, de Vasconcelos AS, da Costa Vilhena T, da Silva TL, da Silva Barbosa A, Gomes AR, et al. Oxidative stress in Alzheimer's disease: should we keep trying antioxidant therapies? Cell Mol Neurobiol 2015; 35(5): 595-614. doi: 10.1007/s10571015-0157-y.

4. Khanahmadi M, Farhud DD, Malmir M. Genetic of Alzheimer's disease: a narrative
هر كدام جداكانه بـر سيسـتمهــاى نـورونى مجزايسى اثـر

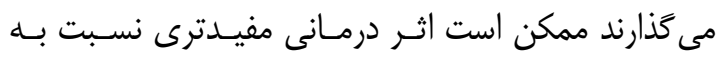

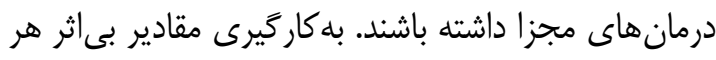

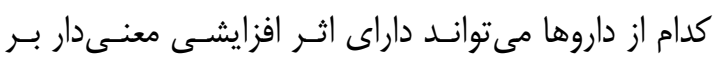

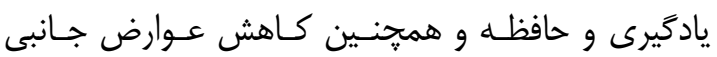
جداكانه هر كدام از داروها باشد.

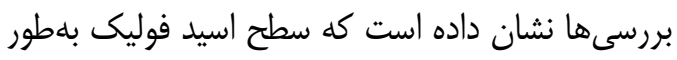

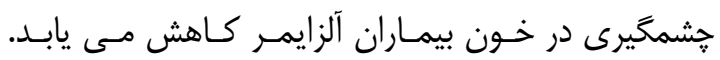
كاهش سطح اسيد فوليك بلهور قابل توجهى نـوروزئز

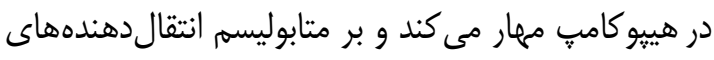

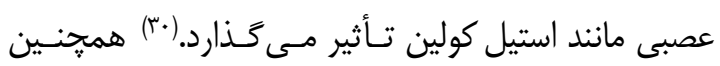

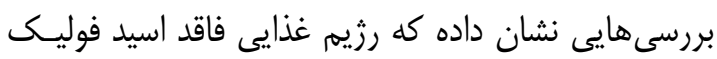
منجر به كاهش سطح نوروترانسميتر استيل كولين در ناحيه

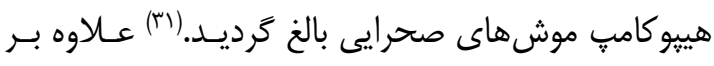

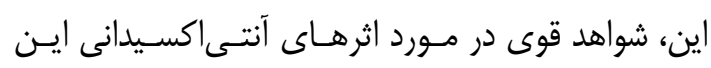

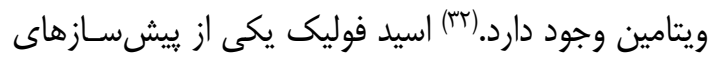

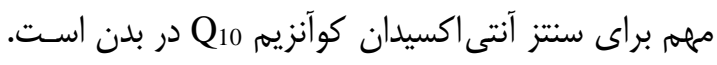

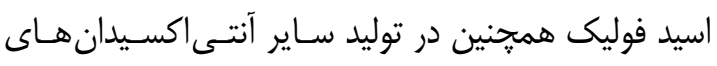

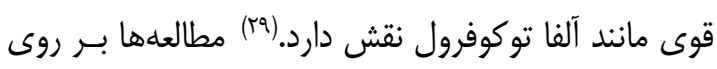

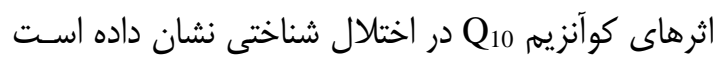

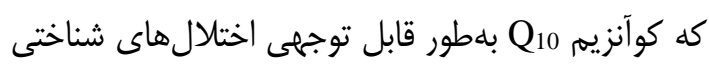

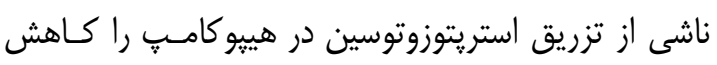
مى دهد. (سT) مطالعههاى قبلى نشان داده است كه يِيش درمـان بـا

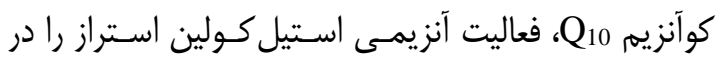

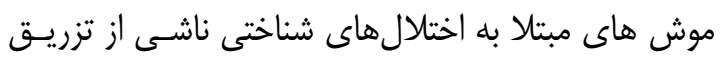

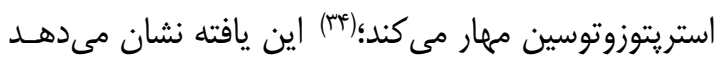

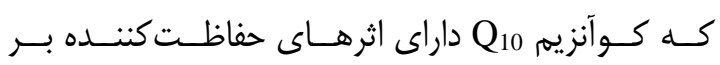
نورون هاى كولينرزيك مى باشد. در مطالعه حاضـر، تيمـار

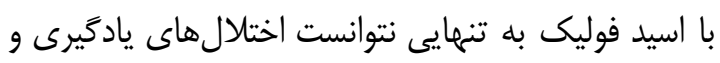

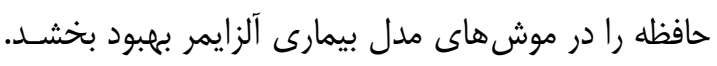

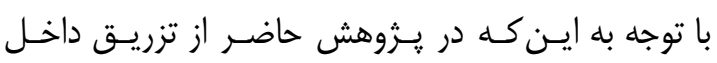

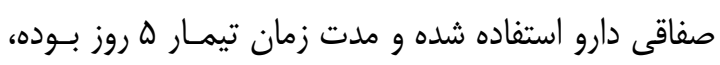

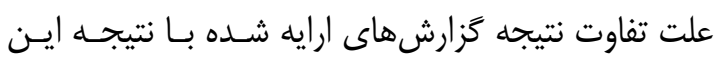


review article. Iran J Public Health 2015; 44(7): 892-901.

5. An Y, Zhang C, He S, Yao C, Zhang L, Zhang Q. Main hypotheses, concepts and theories in the study of Alzheimer's disease. Life Sci J 2008; 5(4): 1-5.

6. Padurariu M, Ciobica A, Lefter R, Serban IL, Stefanescu C, Chirita R. The oxidative stress hypothesis in Alzheimer's disease. Psychiatr Danub 2013; 25(4): 401-9.

7. Geula C, Nagykery N, Nicholas, A, Wu $\mathrm{CK}$. Cholinergic neuronal and axonal abnormalities are present early in aging and in Alzheimer's disease. J Neuropathol Exp Neurol 2008; 67(4): 309-18. doi: 10.1097/ NEN. 0b013e31816a1df3.

8. Selden NR, Gitelman DR, SalamonMurayama N, Parrish TB, Mesulam MM. Trajectories of cholinergic pathways within the cerebral hemispheres of the human brain. Brain 1998; 121(12): 2249-57.

9. Bartus RT, Dean RL, Beer B, Lippa AS. The cholinergic hypothesis of geriatric memory dysfunction. Science 1982; 217(4558): 408-14. doi: 10.1126/science. 7046051.

10. Borlongan CV. Recent preclinical evidence advancing cell therapy for Alzheimer's disease. Exp Neurol 2012; 237(1): 142-6. doi: 10.1016/j.expneurol.2012. 06.024 .

11. Gutteridge JM. Lipid peroxidation and antioxidants as biomarkers of tissue damage. Clin Chem 1995; 41(12 Pt 2): 1819-28.

12. Hernandez-Diaz S, Werler MM, Walker AM, Mitchell AA. Folic acid antagonists during pregnancy and the risk of birth defects. N Engl J Med 2000; 343(22): 1608-14. doi: 10.1056/NEJM200103223441212.

13. Nakatomi $H$, Kuriu $T$, Okabe $S$, Yamamoto S, Hatano O, Kawahara N, et al.
Regeneration of hippocampal pyramidal neurons after ischemic brain injury recruitment of endogenous neural progenitors. Cell 2002; 110(4): 429-41. doi: 10.1016/S0092-8674(02)00862-0.

14. Rauscher FM, Sanders RA, Watkins JB 3rd. Effects of coenzyme-Q10 treatment on antioxidants pathways in normal and streptozotocin-induced diabetic rats. $\mathrm{J}$ Biochem Mol Toxicol 2001; 15(1): 41-6. doi: 10.1002/1099-0461(2001)15:1<41.

15. Ashkavandi S, Moazedi AA, Semnanian S, Harooni H, Pourmehdi M. Effects of GM1 ganglioside on the recovery of spatial learning after a lesion of the nucleus basalis magnocellularis in an experimental model of Alzheimer's disease in adult male rats. American J Medicine and Medical Sciences 2015; 5(1): 42-7. doi: $10.5923 / \mathrm{j}$. ajmms.20150501.08.

16. Montero-Pastor A, Vale-Martinez A, Guillazo-Blanch G, Marti-Nicolovius M. Effect of electrical stimulation of the nucleus basalis on two-ways active avoidance acquisition, retention and retrieval. Behav Brain Res 2004; 154(1): 41-54. doi: 10.1016/ j.bbr.2004.01.017.

17. Cosquer B, Vasconcelos AP, Frohlich J, Cassel J.C. Blood-brain barrier and electromagnetic fields: effects of scopolamine methylbromide on working memory after whole body exposure to $2.45 \mathrm{GHZ}$ microwaves in rats. Behav Brain Res 2005; 161(2): 229-37. doi: 10.1016/j.bbr.2005.02. 025.

18. Davis CP, Franklin LM, Johnson GS, Schrott LM. Prenatal oxycodone exposure impairs spatial learning and/or memory in rats. Behav Brain Res 2010; 212(1): 27-34. doi: 10.1016/j.bbr.2010.03.022.

19. Luine VN, Frankfurt M. Estrogen 
facilitate memory processing through membrane mediated mechanisms and alterations in spike density. Front Neuroendocrinol 2012; 33(4): 388-402. doi: 10.1016/j.yfrne. 2012.07.004.

20. Liu P, Bilkey DK. The effect of NMDA lesions centered on the postrhinal cortex on spatial memory tasks in the rat. Behav Neurosci 2002; 116(5): 860-73.

21. Gratwicke J, Kahan J, Zrinzo L, Hariz M, Limousin P, Foltynie T, et al. The nucleus basalis of Meynert: a new target for deep brain stimulation in dementia? Neurosci Behav Rev 2013; 37(10 Pt 2): 2676-88. doi: 10.1016/j.neubiorev. 2013.09.003.

22. Nyakas C, Granic I, Halmy LG, Banerjee P, Luiten PG. The basal forebrain cholinergic system in aging and dementia rescuing cholinergic neurons from neurotoxic amyloid $\beta \mathrm{A}-42$ with memantine. Behav Brain Res 2011; 221(2): 594-603. doi: 10.1016/j.bbr. 2010.05.033.

23. Rabiei Z, Rafieian-Kopaei M, Heidarian E, Saghaei E, Mokhtari S. Effects of Zizyphus jujube extract on memory and learning impairment induced by bilateral electric lesions of the nucleus basalis of meynert in rat. Neurochem Res 2014; 39(2): 353-60. doi: 10.1007/s11064-013-1232-8.

24. Zahedi M, Hojjati MR, Fathpour H, Rabiei Z, Alibabaei Z, Basim A. Effect of rheum ribes hydro-alcoholic extract on memory impairments in rat model of Alzheimer's disease. Iran J Pharm Res 2015; 14(4): 1197-206.

25. Lindner MD, Hogan JB, Hodges DB Jr, Orie AF, Chen P, Corsa JA, et al. Donepezil primarily attenuates scopolamine-induced deficits in psychomotor function, with moderate effects on simple conditioning and attention, and small effects on working memory and spatial mapping. Psychopharmacology (Berl) 2006; 188(4): 629-40. doi: 10.1007/s00213-006-0556-3.

26. Sharma B, Singh N, Singh M. Modulation of celecoxib and streptozotocin-induced experimental dementia of Alzheimer's disease by pitavastatin and donepezil. J Psychopharmacol 2008; 22(2): 162-71. doi: $10.1177 / 0269881107081553$.

27. Kroker K, Rast G, Giovannini R, Marti A, Dorner-Ciossek C, Rosenbrock H. Inhibition of acetylcholinestrase and phosphodiesterase9A has differential effects on hippocampal early and late LTP. Neuropharmacology 2012; 62(5-6): 1964-74. doi: 10.1016/j. neuropharm.2011.12.021.

28. Barkats M, Millecamps S, Abrioux P, Geoffroy MC, Mallet J. Overexpression of glutathione peroxidase increases the resistance of neuronal cells to Abeta-mediate neurotoxicity. J Neurochem 2000; 75(4): 1438-46.

29. Dehghani Dolatabadi HR, Reisi P, Alaei H, Azizi Malekabadi H, Pilehvarian AA. Folic acid and coenzyme Q10 ameliorate cognitive dysfunction in the rat with intracerebroventricular injection of streptozotocin. Iran J Basic Med Sci 2012; 15(2): 719-24.

30. Kruman II, Kumaravel TS, Lohani A, Pedersen WA, Cutler RG, Kruman Y et al. Folic acid deficiency and homocysteine impair DNA repair in hippocampal neurons and sensitize them to amyloid toxicity in experimental models of Alzheimer's disease. $\mathbf{J}$ Neurosci 2002; 22(5): 1752-62. doi: https://doi.org/10.1523/JNEUROSCI.22-0501752.2002.

31. Crivello CN, Blusztajn JK, Joseph JA, Shukitt-Hale B, Smith DE. Short-term nutritional folate deficiency in rats has a 
greater effect on choline and acetylcholine metabolism in the peripheral nervous system than in the brain, and this effect escalates with age. Nutr Res 2010; 30(10): 722-30. doi: 10.1016/j.nutres. 2010.09.008.

32. Hernandez-Diaz S, Werler MM, Walker AM, Mitchell AA. Folic acid antagonists during pregnancy and the risk of birth defects. N Engl J Med 2000; 343(22): 1608-14. doi: 10.1056/NEJM200103223441212
33. Lenaz G, Bovina C, Formiggini G, Parenti Castelli G. Mitochondria, oxidative stress, and antioxidant defences. Acta Biochim Pol 1999; 46(1): 1-21.

34. Veerendra Kumar MH, Gupta YK. Effect of Centella asiatica on cognition and oxidative stress in an intracerebroventricular streptozotocin model of Alzheimer's disease in rats. Clin Exp Pharmacol Physiol 2003; 30(5-6): 336-42. 